\title{
AOR
}

Selected Papers of \#AolR2018:

The $19^{\text {th }}$ Annual Conference of the

Association of Internet Researchers

Montréal, Canada / 10-13 October 2018

\section{RECALIBRATING DAILY LIFE: SYNCHRONIZING, COORDINATING, AND SCHEDULING THROUGH SMARTPHONES}

\author{
Martin Hand \\ Queen's University, Canada
}

\section{Background}

There is considerable research on contemporary time and temporality, focusing on changing infrastructures, experiences, and practices associated with networked and mediatized life (Agger, 2011; Couldry \& Hepp, 2017; Keightley, 2013; Wajcman, 2015; Wajcman \& Dodd, 2017). Research has illuminated the changing temporalities of work and home (Gregg, 2011), shifting rhythms of practice and problems of coordination (Southerton, 2009), and new temporalities of disadvantage encountered in everyday life (Sharma, 2014). At the level of critical cultural analysis, such temporal demands appear to produce new anxieties, pushing people to take individual responsibility for coordinating increasing numbers of 'de-synchronized' activities.

This paper argues that people are becoming 'habituated' (Chun, 2016) to new modes of synchronization and coordination largely through smartphones. Smartphones are highly significant material objects that people live with, but also bafflingly complex conduits for a vast array of interconnected media-practice constellations. The paper argues that smartphones are temporalizing devices, like calendars, clocks, and cameras, but they have become recursive elements within almost every other social practice, potentially altering the temporal qualities of those practices, their coordination, and the temporal data produced as a result.

This paper examines individual framings and experiences of temporal management via smartphone applications. It asks: to what extent and in what ways do configurations of smartphones and scheduling applications intervene in and restructure the temporality of practices and people's experiences of time?

\section{Method}

Hand, M. (2018, October 10-13). Recalibrating Daily Life: Synchronizing, Coordinating, and Scheduling through Smartphones. Paper presented at AoIR 2018: The $19^{\text {th }}$ Annual Conference of the Association of Internet Researchers. Montréal, Canada: AolR. Retrieved from http://spir.aoir.org. 
The paper draws upon in-depth semi-structured interview material with professional urban and suburban householders $(\mathrm{N}=25)$, individuals transitioning to retirement $(\mathrm{N}=20)$, and university students $(\mathrm{N}=25)$ to examine how a range of temporal expectations are perceived, articulated, and negotiated in practice. Interviews included talking through temporal data of many kinds on personal devices. The guiding analytic questions were: where do identifiable expectations about temporal synchronization, coordination, duration, reciprocity, and productivity come from? What are the relations between institutionally defined and subjective experiences of temporal ordering? Does data produced through daily activities alter the temporal contours of those activities? Are social actors reorienting themselves in-time, in relation to mediatized temporal expectations? Participants discussed the organization of mundane daily activities, strategies of temporal negotiation and management, emotional and material divisions of labour, feelings about temporal experience, perceptions of and expectations about time, and so forth.

\section{Findings: Recalibrations}

This preliminary qualitative analysis identifies four emerging modes of temporal management. Following Sharma (2014), these are expressed here as 'recalibrations', stressing the ways in which different temporal demands are encountered, involving alternative efforts to synchronize different elements of daily life through interconnected smartphone anchored applications. All participants spoke of temporal change and adjustment in relation to devices and apps, but with quite different emphases.

\section{Managing precariousness}

For some participants, especially those working multiple 'casual' jobs, or in uncertain part-time service work, specific scheduling applications (e.g. Shiftworker) are used to manage several interlocking forms of precariousness, including finance, shift patterns, and health. This often involves considerable individual orchestration of time in the face of changing institutional demands. Scheduling apps construct colour coded patterns requiring continual adjustment - recalibration - where there is no routine. As such, for many participants, life is a sequence of shifting time slots. All activities must be accurately 'timed', to be scheduled. Without these apps, the work would still be precarious, but it becomes intensely calibrated and organized here - which impinges on much of the day, and transforms other activities into visual temporalized data.

\section{Synchronizing (to) the times of others}

Others are trying to manage broader interconnected systems of synchronization, operating via the smartphone, that pull together multiple environments (work, home, cars), people (co-workers, children, partners, friends), and practices (administration, eating, exercise, driving) daily. Intense forms of recalibration are taking place here, as schedules across multiple locations are 'synced', organizing the sequencing of activities and flows of people. There are multiplying systems (e.g. work office, mobile office, family calendars) with different temporalities that require collective orchestration. It is not only that work bleeds into leisure, but that successful coordination increasingly involves datafication, in turn tending toward continual adjustment. Life here is a 
successful meshwork of coordinated scheduling systems, mixing mono and poly chronic temporal practices.

\section{Temporal self-disciplining}

Many younger participants (though not exclusively) enact the always-on, fluid, chronoscopic time discussed in much of the literature, but always in relation to specific linear projects of self-disciplining and 'improvement'. The use of scheduling applications in conjunction with self-tracking devices and applications produces an intense focus on the present, but aimed at a future (fitter, more organized, productive) self. The temporality here is figured as individualized productivity through comparative data analytics (vs. friends, relatives). Bodily discipline is coupled with episodic multiplication, where each discrete temporal moment 'produced' by the app is an opportunity for 'achievement'. For some, friendships are maintained through scheduling. Life here is a series of goal-meeting actions, where continual data about the self becomes a key resource for self-analysis.

\section{Filling in future time}

For others, there is far more (often normative) clarity about temporal boundaries and what should be scheduled or unplanned. Although the same devices and applications are present, they have a far less central role in the coordination of daily life. There is a related ambivalence about temporal data, or the 'fear' of 'wasting time'. When the established patterns of days, weeks, months are not subject to chronic uncertainty, or complex planning and orchestration, there are other temporalities that take precedence, such as being 'open' to events and surprises. This can often be due to changes in life circumstances (separation, children leaving, etc.), or simply the security of privilege, enabling a self-conscious 'taking', 'wasting', and 'filling in' of time. Life here is the emptying out of temporal obligations.

\section{Discussion}

These findings suggest that some broad dimensions of contemporary mediatized temporality - speed, acceleration, feeling 'pressed for time' - become materialized in people's daily lives in complex ways that increasingly require individual coordination. However, there are multiple sources of temporal expectations, from the changing demands of precarious work to an increased number of children's activities. The interview data tells us a lot about a series of habits in formation, about how people with different classed and gendered temporal advantages adjust to complex temporalities, and how they are materialized in smartphone apps and varied connected systems. This is mostly experienced as an intensification of broader shifts in temporal demand, which is at the same time being 'produced' through efforts to synchronize daily life.

\section{References}

Agger, B. (2011) 'iTime: Labour and life in a smartphone era', Time \& Society, 20(1): 119-136. 
Chun, W. H. K. (2016) Habitual Media: updating to remain the same, Cambridge, MA: MIT Press.

Couldry, N. Hepp, A. (2017) The Mediated Construction of Reality, Cambridge: Polity.

Gregg, M. (2011) Work's Intimacy, Cambridge: Polity Press.

Keightley, E. (2013) 'From immediacy to intermediacy: The mediation of lived time,' Time \& Society, 22(1): 55-75.

Sharma, S. (2014) In the meantime, Durham, NC: Duke University Press.

Southerton, D. (2009) 'Re-ordering temporal rhythms,' in E. Shove, F. Trentmann, \& R. Wilk (Eds.), Time, consumption and everyday life, Oxford, UK: Berg, pp. 56 - 73.

Wajcman, J. (2015) Pressed for time, Chicago, IL: Chicago University Press.

Wajcman, J. Dodds, N. (2017) The Sociology of Speed, Oxford: Oxford University Press. 